\title{
On Research Challenges in Hybrid Medium Access Control Protocols for IEEE 802.15.6 WBANs
}

\author{
Abdul Saboor ${ }^{1}$, Rizwan Ahmad ${ }^{1}$, Waqas Ahmed ${ }^{2}$, Adnan K Kiani ${ }^{1}$, Yannick Le Moullec ${ }^{3}$ Muhammad Mahtab \\ Alam $^{3}$ \\ ${ }^{1}$ School of Electrical Engineering and Computer Science, National University of Sciences and Technology \\ (NUST), Islamabad, Pakistan \\ ${ }^{2}$ Pakistan Institute of Engineering and Applied Sciences (PIEAS), Islamabad, Pakistan \\ ${ }^{3}$ Tallinn University of Technology, Tallinn, Estonia \\ Email:[asaboor.msit15seecs, rizwan.ahmad, adnan.khalid]@seecs.edu.pk, waqas@ pieas.edu.pk, [yannick.lemoullec, \\ muhammad.alam]@ttu.ee
}

\begin{abstract}
IEEE 802.15.6 is a Wireless Body Area Network (WBAN) standard proposed to facilitate the exponentially growing interest in the field of health monitoring. This standard is flexible and outlines multiple basic Medium Access Control (MAC) protocols that are contention based and collision free to meet the WBAN Quality of Service (QoS) challenges. Typically, current research trends in WBAN MAC focus on designing a hybrid MAC that is a combination of basic MAC protocols. In this paper, we provide a first detailed survey of existing hybrid MAC protocols based on IEEE 802.15.6 which would be useful for the related research community. Firstly, the paper lists the design challenges of a WBAN MAC. Secondly, it highlights the significance of hybrid MAC protocols in meeting the design challenges while comparing them to standard MAC protocols. Thirdly, a critical and thorough comparison of existing hybrid MAC protocols is presented in terms of network QoS and WBAN specific parameters. Lastly, we identify key open research areas that are often neglected in hybrid MAC design and further propose some possible directions for future research.
\end{abstract}

Keywords-Hybrid MAC, Remote Monitoring, Wireless Body Area Network (WBAN), Time Division Multiple Access (TDMA), Carrier Sense Multiple Access/Collision Avoidance (CSMA/CA), Emergency Traffic (ET), Quality of Service (QoS)

\section{INTRODUCTION}

Over the past few years, advancements in Information and Communication Technology (ICT) have resulted in improvement of patient management such as disease diagnostics, monitoring, and automated data collection. As a result, an increased life expectancy is observed in many areas of the world. Currently, $11.7 \%$ of the world population is above 60 years of age and it is expected to reach around $21.1 \%$ by the end of 2050 [1]. Many in this age group suffer from multiple non-communicable diseases such as cancer, diabetes and heart disease which alone caused $68 \%$ deaths in people above 60 years of age in 2012 [2]. According to a survey, old age increases the medical expenses to around $17.9 \%$ of US Gross Domestic Product (GDP) in 2012, thus imposing a huge burden on the health care system [3]. Early detection of such diseases is important to speed up the diagnosis that can significantly reduce the risk of mortality and health related costs [4].

Wireless Body Area Network (WBAN) has emerged as a definite solution to increase the quality of health care and subsequently decrease the cost of patient monitoring, and management. WBAN is an accumulation of small, energy efficient, low cost, robust implanted and wearable sensors equipped with wireless communication devices [5]. IEEE 802.15.6 WBAN standard supports sensors with a different range of applications such as heart rate, blood flow, blood Potential Hydrogen ( $\mathrm{PH})$ and body temperature etc [6]. This standard is generally developed for medical applications, however, it also supports other applications such as e-sports, e-emergency, e-fitness, e-entertainment, e-gaming, defence, electronics and social [7], [8]. The main applications of IEEE 802.15.6 WBAN are shown in Fig. 1. In IEEE 802.15.6 WBAN, implanted devices can be used to monitor blood pressure, blood sugar, Electrocardiogram (ECG), Electroencephalogram (EEG) etc., and can provide accurate and timely information to the doctors. Similarly, wearable devices can be used to monitor an athlete's body posture, vitals, fitness and provide other health information [9]. Both the implanted and wearable devices continuously monitor, gather and forward vital information to the server for health monitoring at home [10], [11]. In addition to the above applications, IEEE 802.15.6 WBAN also supports nanomedical applications such as emotion detection, biometric authentication, real-time audio and video streaming and emergencies [12].

Typically, WBAN has a three-tier architecture as shown in Fig. 2 [13]. The first tier consists of WBAN sensors that are implanted in or on the human body and gather live data. The second tier is a base unit where most of the processing is done; it can be a mobile device with internet connectivity. The third tier is where data is made available to the hospital, telemedicine server [14] and doctor who can remotely analyze the state of patients. WBAN generally follows a star topology where the sensor nodes are directly connected to a coordinator. The standard also supports two-hop communication between nodes and the hub to overcome issues, such as channel attenuation [15].

Initially, wireless body area devices employed Wireless Personal Area Networks (WPANs) (IEEE 802.15.4) Medium Access Control (MAC) for the purpose of sensing and communicating data on a person's body [16], [17]. However, the requirements and specifications of WBAN such as energy 


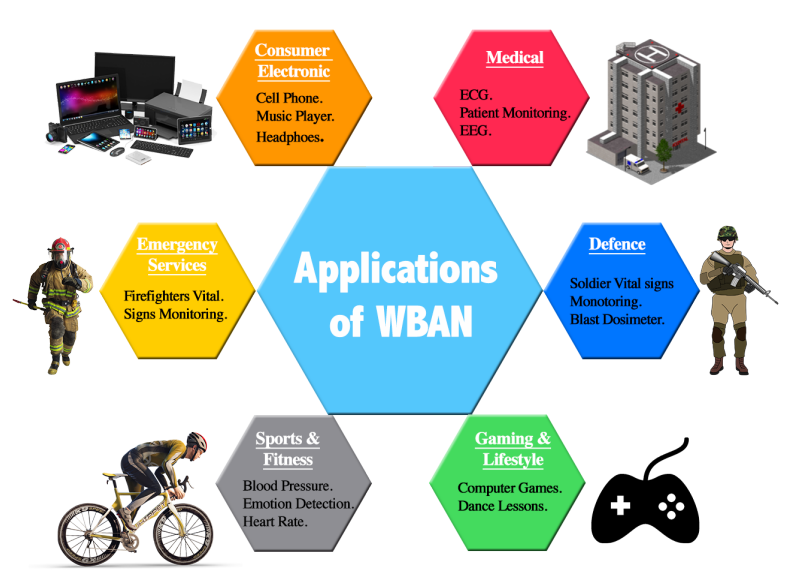

Fig. 1. Applications of IEEE 802.15.6 WBAN.

consumption, lifetime, latency, heterogeneous traffic and scalability [18], initiated an effort within the IEEE community to come up with a new standard. In 2012 WBAN IEEE 802.15.6 standard was introduced [19]. There are still multiple technical and social challenges that must be addressed for complete adoption of WBAN. The technical challenges have led to various implementations and design opportunities at the MAC layer. For example, a radio transceiver is the most energy consuming component [20] in a WBAN sensor node. The activity of a radio transceiver is controlled by the MAC layer. Therefore, in a scenario where there are multiple WBAN devices on a body, the design of an intelligent and topology resilient MAC protocol is the key to achieve necessary throughput, energy efficiency, delay and security. In addition, this MAC protocol must be able to handle various categories of traffic generated by WBAN devices such as Emergency Traffic (ET) and Normal Traffic (NT). In the existing literature, the basic strategies to design an efficient MAC are contention based MAC and collision free MAC protocols. Generally, for different traffic types of WBAN, these MAC protocols can only optimize few Quality of Service (QoS) parameters. For example, contention based MAC protocols monitor the channel continuously which makes the protocol resilient to changes in the topology, however, continuous sensing reduces energy efficiency and thus the overall lifetime of the sensors. In addition, using contention based MAC for ET due to possible collisions is not recommended. The problems of energy efficiency, reliability and traffic can be resolved by using scheduling based MAC protocols, however, their performance degrades when topology changes rapidly or when the number of node increases.

In order to overcome the limitation of basic MAC protocols, hybrid MAC protocols have been proposed in the literature to optimize multiple QoS parameters while simultaneously meeting the traffic requirements. Hybrid MAC combines salient features of the basic protocols, which can be tailored according to the application requirements, thus making it more suitable for application aware deployment. In this paper, a thorough survey of hybrid MAC protocols for WBAN application is provided. To the best our knowledge, this is the first survey on IEEE 802.15.6 based hybrid MAC protocols. The existing

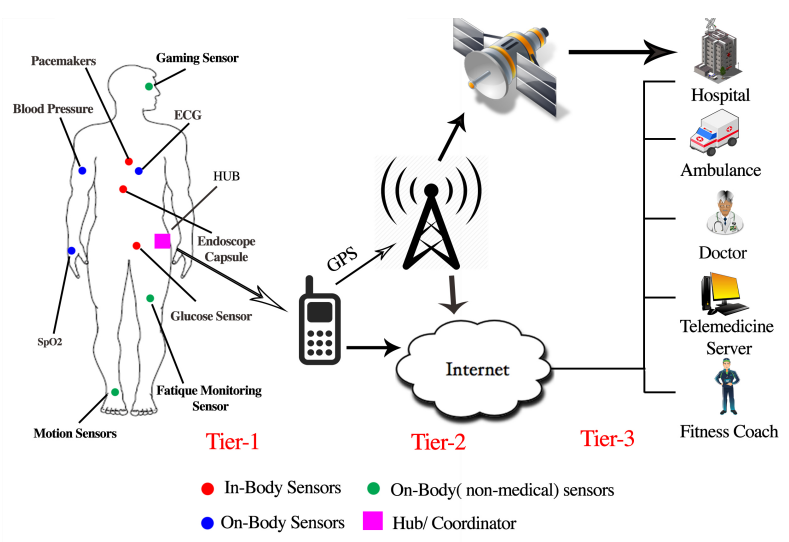

Fig. 2. Typical three-tier architecture of WBAN.

survey papers on WBAN MAC are limited to the basic MAC protocols mentioned above. The main contributions of this paper are as follows:

1. It provides a comparison of basic access and hybrid MAC protocols in terms of energy efficiency, bandwidth utilization, synchronization etc.

2. It provides a classification of existing hybrid MAC protocols based on the combination of basic access mechanisms and highlights the main design challenges of WBAN MAC.

3. It investigates and compares existing IEEE 802.15.6 WBAN hybrid MAC protocols. This comparison is made in terms of energy efficiency, throughput, delay, security, network lifetime, channel type and etc.

4. It highlights open research challenges and possible directions for future research such as energy harvesting, opportunistic communication, security and interference etc.

The rest of the paper is organized as follows: Section II introduces IEEE 802.15.6 MAC layer design challenges. Section III presents IEEE 802.15.6 MAC along with its variants and shows a comparison of different access mechanisms. A brief explanation of existing IEEE 802.15.6 hybrid MAC protocols and a comprehensive comparison along with some potential future directions are given in Section IV. Finally, Section V presents detailed conclusions.

\section{Design Challenges of IEEE 802.15.6 MAC}

IEEE proposed a new standard, IEEE 802.15.6, in 2012 that enables ultra low power wireless sensor devices to operates in and around the human body. The main features of this standard include provision of: multiple data rates, node and traffic priority, multiple radio interfaces and access methods.

The IEEE 802.15.6 MAC layer is responsible to perform following tasks [19]:

1. Frame Processing

2. Access Classification and Division

3. Body Area Network (BAN) creation/operation and node connection/disconnection

4. Random Access

5. Improvised access and unscheduled access 
6. Scheduling access and scheduling-polling access and

7. Access Contention, termination and timeout

The standard supports three different kinds of superframe modes as shown in Fig. 3 [21]. The beacons are used to define the length of a superframe. The first mode (Fig. 3(a)) uses beacon mode with superframe boundaries and it consist of Contention Access Phase (CAP), Random Access Phase (RAP), Managed Access Phase (MAP) and Exclusive Access Phase (EAP). Both the EAP and MAP are used to facilitate high priority traffic while CAP and RAP facilitate all kinds of traffic. The second mode is a non-beacon mode (Fig. 3(b)) with superframe boundaries that falls in the MAP duration. Instead of transmitting beacons to define boundaries, polling is used to define the transmission time of each node. The coordinator schedules transmission for each node in such a way that it does not exceed superframe boundaries. In the third mode (Fig. 3(c)), a pre-defined frame boundary is not used. The coordinator allocates slots to nodes through a polling mechanism. Multiple mechanisms are used to provide access to a shared medium like random access using slotted ALOHA and Carrier Sense Multiple Access/Collision Avoidance (CSMA/CA). In the case of an unscheduled access, the coordinator sends polling commands (without pre-reservation) to schedule the shared channel access.

Rich in features, this WBAN standard addresses the deficiencies of previous standards. However, there are still challenges that need to be addressed to achieve any significant performance gain. Furthermore, the application oriented design also adds complexity. Some of these challenges are:

- Security: Security is one of the key requirements of WBAN as different patient's data should not be mixed and authentic information must be delivered to the required destination [22]. The implementation of a secure key management system [23] can be a potential solution to this problem. It works on the principle of public and private keys. The public key is shared with everyone while a unique private key for encryption/decryption is kept secret. Authentication and encryption using light weight protocols at MAC can also assist this process.

- Reliability: This term usually refers to packet loss probability and transmission delay which depends on the channel condition and traffic requirements. Reliability can be improved by implementing robust and error resilient

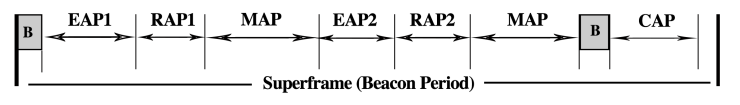

a) IEEE 802.15 .6 beacon mode with superframe
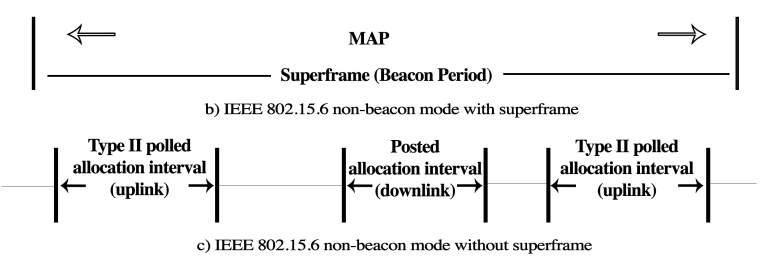

Fig. 3. IEEE 802.15.6 Superframe Structures [21]. transmission mechanisms, implementing re-transmission algorithms and adaptive scheduling schemes [24].

- Throughput: In a WBAN, the throughput reduces due to collision, loss of connectivity and dynamic human activities. Some applications require high throughput, for example ECG sensors that require throughput in the range of $150 \mathrm{Kbps}$. The different throughput requirements of WBAN devices can be achieved by incorporating traffic priorities and efficient scheduling algorithms [25].

- Body Posture: Unpredictable movements of the human body and posture changes can significantly degrade the performance of a WBAN. In these scenarios, cooperative communication using a relay helps in managing outages due to mobility and posture changes.

- Interference: There is a need for reducing interference for the smooth coexistence of body sensors [26]. This is critical in large-scale and dense deployments of WBANs such as hospital or medical facility. The intra-WBAN interference can be controlled by coordinating and intelligently mixing different access modes.

- Scalability: WBAN should be scalable to cater for any changes in the number of nodes [27]. The MAC layer is responsible to provide scalability while maintaining the desired performance.

- Latency: The latency specifications are different for each traffic type in WBAN. Generally, latency must be minimum in order to reduce energy consumption and facilitate ET.

- Lifetime Issues: WBANs are energy critical and often the sensor nodes are implanted in a human body. It is impossible to remove them from the body for charging [27]. There are certain states of the sensor that can cause more energy consumption such as idle listening, overhearing, packet collision and packet overhead. Energy efficient algorithms are required [26] [28] and can be complemented by incorporating an energy harvester.

The requirements discussed above can be resolved by modifying the MAC of IEEE 802.15.6 [29-31]. For example, introducing sleeping or energy saving/harvesting on MAC layer can resolve lifetime and maintenance issues. The provision of sensor or traffic priority can help improve data flow and help to reduce collisions. Security can be improved by introducing encryption in MAC layer.

\section{802.15.6 MAC PROTOCOLS}

The MAC layer of IEEE 802.15.6 can be classified as Collision free and Contention based. The combination of any of these techniques can lead to a hybrid mechanism.

\section{A. Collision Free MAC Protocols:}

Collision Free MAC Protocols are further classified into two protocols.

1) Scheduling Based MAC Protocols: Scheduling based MAC protocols are the most commonly used protocols. They use TDMA to enable multiple node transmission on the same channel without collision. The time is divided into slots and at least one slot is assigned for a node to transmit its signals. 
With TDMA, a node will only turn on its radio when it needs to transmit or receive a signal, thus TDMA also provides low duty cycle operations. One of the drawbacks of traditional TDMA is the synchronization of the nodes and adaptation to topology changes that consumes energy. Moreover, all the nodes must agree prior to the slot assignments, which is a challenging task. In addition, asymmetric traffic requirements of WBAN devices can cause delay.

2) Polling Based MAC Protocols: Polling is also a type of scheduling based protocol. It generally uses Type I/II (scheduled/unscheduled) phases for uplink allocation intervals, downlink allocation intervals and bi-link allocation intervals. Type I and Type II access phases can be differentiated by the units of allocations. In Type I, devices request time intervals, whereas, in Type II devices request number of frames. In scheduled transfers, the nodes use their allocated time slots for data transmission while poll/post command is sent by a coordinator to allocate resources in unscheduled transfers. In a beacon or non-beacon mode with superframe boundaries, unscheduled bi-link allocations may be 1-periodic (one or more allocation intervals in every superframe) or $m$-periodic allocations (one or more allocation intervals in every $m$ superframe and $m$ should be larger than 1). A node can not have both 1-periodic and $m$-periodic allocations in the same BAN. In a non-beacon mode without superframes, unscheduled bi-link allocations may only be 1-periodic. These protocols are usually scheduling based and employ a masterslave configuration. A central coordinator schedules all the transmissions to avoid any collisions. It is more flexible than TDMA and has the tendency to accommodate multiple traffic sources with different inter-arrival rates. Both the scheduling and polling based MAC protocols allow collision free network access.

\section{B. Contention Based MAC Protocols:}

Contention based MAC protocols do not rely on fixed time slots for data transmissions. The nodes that have data to transmit contend with each other to gain medium access. These protocols are usually CSMA/CA based and are simple, flexible and robust. To send information, the nodes do not require global topology or synchronization information and also they can enter or leave the network without any hindrance. The main advantage of using contention protocols over scheduling protocol is that they can identify the traffic/density changes more easily and can allocate resources on demand. With frequently changing topologies, these protocols are more flexible and peer-to-peer communication is directly maintained here. One eminent shortcoming of contention protocols is the wastage of energy resources due to collisions/contentions.

\section{Hybrid MAC Protocols}

The collision free and contention based protocols are combined to form hybrid MAC protocols in IEEE 802.15.6. The hybrid MAC protocols are designed on the premise that combining salient features of aforementioned protocols can overcome the limitations of an individual protocol at the cost of a complex MAC design. In this paper, we summarize the

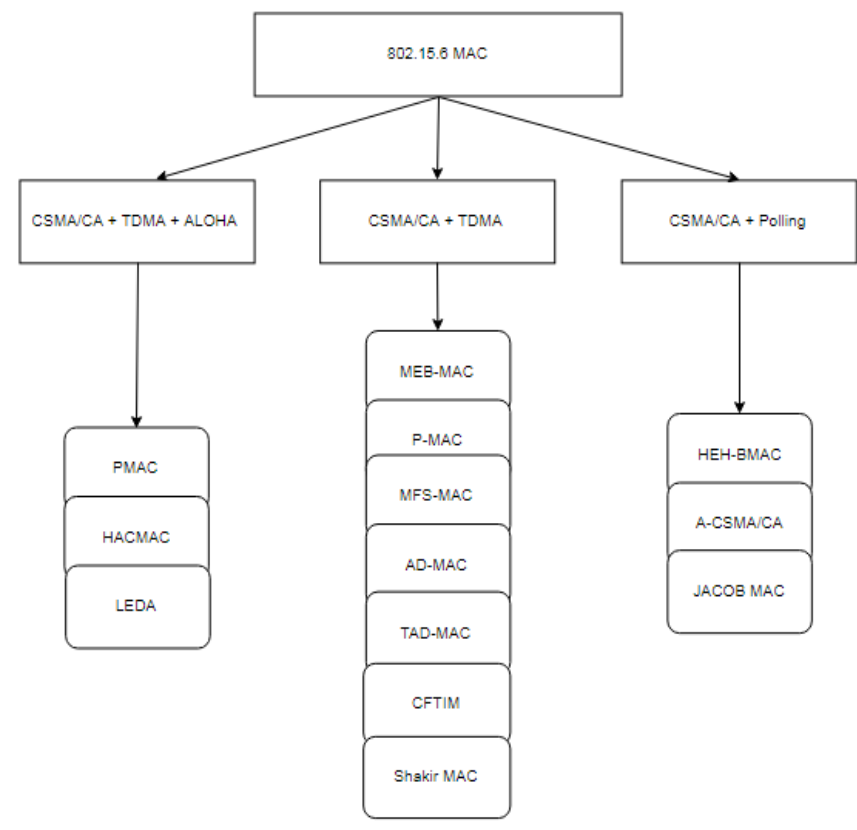

Fig. 4. Classification of Hybrid MAC protocols.

performance of MAC protocols in terms of reliability, latency, QoS and energy efficiency. A comprehensive comparison of all the approaches including hybrid MAC is given in Table I by extending preliminary work in [30], [32-34].

\section{IEEE 802.15.6 HYBRID MAC PROTOCOLS}

This section presents an overview of available IEEE 802.15.6 based hybrid MAC protocols. There are many possible variants of hybrid protocols and these are highlighted in Fig. 4. In these following subsections, we critically analyze each of them.

1) MEB-MAC [35]: Medical Emergency Body MAC (MEB-MAC) is designed to improve the quality of ET, which is generally small and less frequent. Therefore, the EAP is removed and short frames are used for ET, which enhances the overall throughput. It is argued that both RAP1 and RAP2 cannot be used for ET because there is a chance of a loss or collision. The coordinator introduces multiple listening windows on the MAP to cater for ET. The emergency devices can transmit their data in listening windows without informing the coordinator using TDMA. Hence, it can guarantee reliability and improves access time. The duration of access phases is dynamic and it is defined by the application requirements. The traffic is classified on the basis of severity and a backoff timer is assigned accordingly. The coordinator keeps track of all the ET requests in the MAP and multiple slots are introduced in listening windows on the basis of their appearance in the MAP to accommodate ET traffic needs.

Drawbacks: The MEB-MAC protocol has higher energy consumption which reduces the lifetime of sensors. This is mainly due to the removal of EAP and dynamic access period in MAC. 
TABLE I

COMPARISON OF DIFFERENT ACCESS MECHANISMS IN 802.15.6 MAC.

\begin{tabular}{|l|l|l|l|l|l|l|l|l|l|l|}
\hline Approaches & $\begin{array}{l}\text { Reliability } \\
\text { Support }\end{array}$ & $\begin{array}{l}\text { Energy } \\
\text { Effi- } \\
\text { ciency }\end{array}$ & $\begin{array}{l}\text { Real } \\
\text { Time } \\
\text { Commu- } \\
\text { nication }\end{array}$ & $\begin{array}{l}\text { Bandwidth } \\
\text { Utiliza- } \\
\text { tion }\end{array}$ & $\begin{array}{l}\text { Synchroniz- } \\
\text { ation }\end{array}$ & $\begin{array}{l}\text { Body } \\
\text { Posture }\end{array}$ & $\begin{array}{l}\text { Power } \\
\text { Consump- } \\
\text { tion }\end{array}$ & $\begin{array}{l}\text { Traffic } \\
\text { Level }\end{array}$ & $\begin{array}{l}\text { Packet } \\
\text { Delay }\end{array}$ & $\begin{array}{l}\text { Transmission } \\
\text { Efficiency }\end{array}$ \\
\hline $\begin{array}{l}\text { Contention } \\
\text { Based }\end{array}$ & Good & High & Moderate & Low & N/A & Good & High & Low & Variable & Low \\
\hline $\begin{array}{l}\text { Polling } \\
\text { Based }\end{array}$ & Good & Moderate & Moderate & $\begin{array}{l}\text { Moderate- } \\
\text { High }\end{array}$ & Necessary & Low & Low & $\begin{array}{l}\text { Moderate- } \\
\text { High }\end{array}$ & Fixed & High \\
\hline $\begin{array}{l}\text { Scheduling } \\
\text { Based }\end{array}$ & Good & Low & Low & High & Necessary & Low & Low & High & Fixed & High \\
\hline Hybrid & Good & High & High & $\begin{array}{l}\text { Moderate- } \\
\text { High }\end{array}$ & N/A & Good & Moderate & $\begin{array}{l}\text { Moderate- } \\
\text { High }\end{array}$ & $\begin{array}{l}\text { Variable- } \\
\text { Fixed }\end{array}$ & $\begin{array}{l}\text { Moderate- } \\
\text { Low }\end{array}$ \\
\hline
\end{tabular}

2) P-MAC [36]: In a P-MAC protocol, the coordinator transmits beacons at the start of a superframe to define its boundaries and transmission time. It further defines uplink (UL) and downlink (DL) intervals. The superframe starts with a preamble for synchronization followed by DL and UL subfields. The DL sub-field defines the time of occurrence of the physical layer in the DL subframe, which can be unicast or broadcast. The UL contains the information of each node and defines the transmission probability of each node. It is further subdivided into two parts; TDMA and CSMA. The TDMA mode is divided into two parts; Time Slot Reserved for ET (TSRE) and Time Slot Reserved for Normal traffic (TSRN) to cater both the ET and NT demands. The CSMA mode is divided into CAP which is further subdivided into two control channels, Uplink Control for Emergency traffic (UCE) and Uplink Control of Normal traffic (UCN). The ET can use both the UCE and UCN while the normal traffic can only use UCN. For better performance, new inter frame gaps are introduced. The ET has to wait for Emergency IFS (EIFS) and the normal traffic has to wait for Normal IFS (NIFS) to transmit in UCN. In general, EIFS < NIFS and EIFS also chooses where traffic should go first between TSRN and UCE. The P-MAC protocol facilitates sleep mode to improve energy efficiency. The basic idea of sleep mode is to conserve network energy by tightly coupling the sleeping schedule of all the nodes. A sleep request is sent by a node at the start of a frame in the CAP and the coordinator validates it by sending acknowledgement (ACK) frame. Initially, the node sleeps for $T$ intervals, it wakes up and check if there is no data to transmit, it sleeps again for $T / 2$ intervals and the cycle continues. A node can wake up before $T$ if traffic appears in the UCE of CAP. The coordinator sends ACK to the node after successful data reception and a node can go to sleep again.

Drawbacks: The idea presented in this protocol is theoretical and no concrete results are given to gauge the performance. The overall structure of the superframe is very complex, therefore, the adoption of traffic changes is might be low. In addition to that, the physical implementation of this protocol is itself a challenging task.

3) HEH-BMAC [37]: The HEH-BMAC protocol is developed for Energy Harvesting (EH) capable sensor nodes to improve their lifetime. The Reserved Polling Access (ID-Polling), Probabilistic Congestion random Access (PC-Access) and dynamic scheduling are used to make this protocol aware of changes in network topology and EH rate. The ID-Polling is used for high priority traffic and with a predictable energy source. In this phase, the coordinator sends a polling packet to a specific node with its ID. On a polling packet arrival, the node checks its energy level, if the energy level is not enough to deal with the transmission then the node does not respond to the packet and goes to sleep again. Free slots are assigned to PC-Access phase. However, if the energy requirements are met the node sends a data packet, which is accompanied by an ACK from the coordinator. All the active nodes follow the same process after receiving a polling packet. The PC-Access mode is used for normal traffic and it is only used when slots and sufficient time is available. The nodes using PC-Access mode remains in sleeping phase during a polling process. In this process, the controller broadcasts a control packet containing contention probability. Each node generates a random number against that control packet to decide the transmission. Additive Increase, Multiplicative Decrease (AIMD) technique is used to update the value of congestion probability depending on unsuccessful polling phase or collision [38]. It uses a dynamic table to store the Ids of nodes that helps in prediction of the responsiveness of a node in polling phase. It helps this protocol to improves the scalability. The controller defines ID-Polling and PC-Access phases but the dynamic scheduling algorithm defines the boundaries of these phases. The dynamic algorithm performs two main tasks. Firstly, it assigns transmission time and calculates the duration of data transmission for access phases. In this process, it allocates enough time to each BAN to attain enough energy for transmission. A dynamic table is also maintained by each node which is updated constantly. Thus, the decision of a node to poll or not to poll depends on this table. Secondly, it is responsible to calculate the interval between two ID-Polling periods using the dynamic table. If the calculated time is enough for transmission in PC-Access phase, then this time is exploited for probabilistic contention. Otherwise, the controller remains in idle position and waits for the next ID-Polling period.

Drawbacks: This protocol needs an extra buffer for each BAN. In addition, estimation of energy for each node is a difficult task. It further depends on a continuous EH source. 
The design of an energy harvester is a very complex task and requires many different considerations such as application requirements, type of harvester, traffic frequency and node priority. It also suffers from global time synchronization issue due to large access delay [25].

4) MFS-MAC [39] : The main aim of MFS-MAC is to reduce energy consumption, which is proportional to a number of nodes in WBAN. It consists of four phases; in the first phase, nodes send a beacon to the master (Coordinator), then the coordinator synchronizes with the nodes in the second phase. In the third phase, a channel schedule is developed between the coordinator and nodes. Actual transmission is controlled in the fourth phase. The structure of a superframe of MFS-MAC merges Type I and Type II phases and moves it to the end of the superframe to keep polling to a minimum. Secondly, EAP2 and RAP2 come right after EAP1 and RAP1. If transmission occurs only in EAP1, the node can go to sleep after the transmission to conserve energy. The nodes provide the transmission information to the coordinator so it can synchronize with all the nodes. The advantage of this process is that the coordinator only wakes up when there exists a node with data to send. When all the nodes complete transmissions, the coordinator can go to sleep and wait for the next synchronization.

Drawbacks: This protocol is solely designed from an energy consumption perspective. Therefore, the throughput provided by this is relatively low and access delay is also large as compared to other protocols.

5) PMAC [40]: This protocol uses a beacon at the end of each superframe. A superframe consists of two CAP (CAP1 \& CAP2) and one Contention Free Phase (CFP) along with some security additions. The CAP1 is used to deal with the emergency as well as NT. It uses CSMA/CA or slotted ALOHA depending on application requirements. Priority is assigned to nodes and the value of Contention Window (CW) is set on the basis of these priorities. The CAP2 is used to transmit the pending data of CAP1. It also informs the coordinator about incomplete transmissions of CFP. The CFP consists of multiple TDMA slots to facilitate large traffic like streaming. The nodes that require TDMA slots send requests in CAP, which are assigned in CFP accordingly.

Initially, the coordinator broadcast a beacon to all nodes and only an active node or a node with enough energy responds. The nodes with less energy or with no data to send/receive go to sleep to conserve energy. In CAP1, CSMA/CA is used with different range of CWs depending on the priorities. A node with specific priority selects a random back-off counters from the allocated $\mathrm{CW}$ range. The nodes with high priority have small values of $\mathrm{CW}$ to provide the early transmission opportunity. After sensing the channel idle, each node decrements its value. Another feature is that it doubles its $\mathrm{CW}$ for each failure rather than only odd failures. In terms of security, three security levels are defined: (Unsecured channel level, Authentication level, and Authentication and Encryption level). Initially, the master key is shared between different nodes and then Pairwise
Temporal Key (PTK) is generated for each session on the basis of mutual agreement between nodes. It uses AES-128 encryption to prevent active or passive attachment on data.

Drawbacks: The PMAC is slow in adapting to changes [24]. In addition, there are chances of collision or packet drop in normal traffic flows because of a small CW. Also, it cannot guarantee transmissions for ET because the packet loss probability of ET will increase with the number of nodes.

6) AD-MAC [41]: In AD-MAC, a superframe is divided into three portions, a beacon followed by CAP and CFP with a total of 32 slots. This reduces the complexity of the superframe. The duration of both the phases is dynamically adjusted depending on the rate and data type. The nodes are prioritized and they can get slots with higher probability in CFP. The Hub (Coordinator) sends a beacon for synchronization, power management and to set the length of CAP, CFP and individual slot. The CSMA/CA mode is used in CAP while the TDMA mode is used in CFP. The coordinator allocates slots to the nodes depending on their priority. The nodes with no data to transmit can go to the sleep state to save energy. Three priority levels are defined here from 0 to 2 depending on severity (from maximum to minimum). A priority level 0 is given to the node with a high rate and emergency nature, level ' 1 ' is also for ET while level ' 2 ' is used for normal traffic. Initially, all the nodes are given highest priority and for comparison, a threshold rate is set. If the data rate of nodes is greater than the threshold, they are categorized as high priority nodes and the rest are called normal nodes. The values of the threshold are calculated dynamically to cater for asymmetric traffic. The nodes with highest priorities will have a small range of CW. Finally, the number of slots can be assigned to nodes depending on the priority level.

Drawbacks: The packet loss probability is high and will lead to low throughput in the presence of high traffic or a large number of nodes. This is due to the fact that ranges of $\mathrm{CW}$ are small. A provision to encrypt important data securely is also missing.

7) A-CSMA/CA [42]: A combination of polling and carrier sensing is used in A-CSMA/CA. At first, the coordinator uses a random backoff counter depending upon $\mathrm{CW}$ size and then it performs CCA to avoid intra-WBAN collisions. The MAC frame consists of three parts, a beacon, an uplink and a downlink. A beacon is used for synchronization and it defines the duration of each field and the frame. Other nodes use beacons to fix their network allocation vector (NAV) that indicates how long the medium is busy. The uplink part is composed of CAP and CFP. In the CAP, nodes compete for opportunity using slotted CSMA/CA while the coordinator controls slots in CFP. Adaptive CSMA/CA (A-CSMA/CA) first analyzes the interference level and adjusts the frame length accordingly. It uses AIMD to estimate the interference level [38]. AIMD uses the history of CW size to update its frame size. If the current $\mathrm{CW}$ is greater than the past average $\mathrm{CW}$, then it is assumed that the coordinator is experiencing more interference. In this case, the coordinator reduces its frame size to give more opportunity to ET with the minimum 
collision. It will additively increase its frame size if the value of current $\mathrm{CW}$ is less than the average past $\mathrm{CW}$ to occupy channel for a long duration. On the basis of a beacon, the nodes define their sleep and wakeup times. If the nodes have a packet in their buffer then they can also compete for more than one slot on CFP. A limited sensing protocol is also defined to reduce energy consumption. The basic idea behind this is to sense channel intermediately rather than continuously.

Drawbacks: More priority levels should be defined so fields in a superframe can adjust sizes to facilitate dynamic requirements of different applications and traffic levels as mentioned in IEEE 802.15.6 WBAN Standard.

8) Jacob MAC [43]: In Jacob MAC, a combination of CSMA/CA and polling is used where some nodes use contention access and rest of nodes use polling. The EAP is merged with the RAP in a superframe, hence it is only made up from RAP \& MAP portions. The RAP uses CSMA/CA while polling is used in the MAP portion. User's priority level is defined between 0-7 from lowest to highest and ranges of the $\mathrm{CW}$ are defined accordingly. For polling, two control packets: EPOLL and EPOLLFINISH are used. A node starts transmitting packets once it receives EPOLL packet from the coordinator and it sends EPOLLFINISH when it completes its transmission. Exhaustive polling is used in this protocol that ensures all the packets available at the beginning of polling and all the packets that come during polling can be transmitted. The nodes that are not transmitting any data can sleep to conserve energy. The coordinator computes the sleep time of a node and embeds its value in EPOLL packet. The node extracts this information and behaves accordingly. The different ratios of RAP and polling result a tradeoff between different QoS parameters (such as latency, lifetime and throughput) by using different ratios of RAP and polling. Drawbacks: One problem with Jacob-MAC is that it cannot simultaneously optimize all the QoS parameters. At a time, one or maximum two QoS parameters from access delay, throughput and lifetime can be achieved. There must be some optimal ratio given at which performance of all QoS parameters is maximum.

9) LEDA [44]: Hybrid Lifetime Extended Directional Approach (LEDA) MAC employs a multi-beam directional mode in CSMA/CA and a single-beam directional mode in TDMA for data reservations and transmissions. LEDA increases network reliability and adaptability using Dynamic Polled Allocation Period (DPAP) for burst data transmissions. Data in classified into two categories: burst and normal data. All the nodes in this protocol are equipped with antennas that generally offers single-beam and multi-beam mode of operations. Single-beam allows a single node to transmit at a time. In multi-beam mode, space around human body is divided into multiple independent sectors to facilitate simultaneous transmissions. The hub can switch to different modes based on User Priority (UP), length of data packets and location. All the nodes go to sleep mode when there is no data to send for energy conservation. LEDA superframe is divided into three major phases: Multi-beam Transmission Period (MTP), Single-beam Transmission Period (STP) and Inactive Period. Beacon is transmitted at the start of synchronization. MTP is further split into Request Period (REP) and Notification Period (NTP). Only request frames are sent in REP such as priority, length of packet and location using CSMA/CA. NTP broadcasts the assignment information such as number of slots needed to transmit data. STP is also divided into two parts: Single-beam Data Transmission Period (SDTP) and DPAP. In SDTP, the hub interacts with specific node based on notifications hence interference is reduced. DPAP is used to cater burst traffic that occurs at the end of frame. Inactive mode is used to conserve energy when there is no data to transmit.

Drawbacks: LEDA is typically designed for extending the lifetime of WBAN. It has been observed from results that IEEE 802.15.6 outperforms LEDA in terms of throughput in the presence of low packet arrival rate. This is mainly due to the complex superframe structure.

10) CFTIM [45]: This work targets interference mitigation in WBAN. The CFTIM protocol uses a combined distributed carrier sensing technique with the combination of CSMA/CA and TDMA in relay-assisted intra-WBAN. All the noninterfering nodes use CSMA for coordination, whereas Flexible TDMA (FTDMA) is used for high interfering sources/relays and the coordinator.

The frame is divided into two major portions. The first portion is used by the coordinator to broadcast messages to the nodes while the second portion is used by the nodes for transmitting their messages to the coordinator. The second portion is further divided into two portions, CSMA/CA and TDMA. History of frames is used to avoid interference. The controller allocates slots to a node on the basis of received information. If there are $m$ active nodes (controller has received at least one beacon), the controller allocates $p$ slots, where $(p>m)$. The active nodes use $m$ slots while $p-m$ slots are assigned for new nodes that may come in next superframe on the basis of prediction. The coordinator controls the messages coming from the nodes by managing $p$ slots. It changes the number of slots dynamically depending on requirements. All the nodes start with CSMA/CA after the reception of a beacon from the coordinator. The coordinator further divides the nodes into two types, high interfering (IS) and non-interfering (TS). The TS uses contention access and chooses the best relay to transmit the message. A relay initially checks the ID of node from the slots list, if it finds the ID then it transmits the message at defined slots, else it will allocate a random slot from $p-m$ slots. A node which is a member of IS checks the ID in list and transmits accordingly. If no ID exists in the list, an IS node chooses a random slot from $p-m$ slots. If the transmission fails an IS node can retry until a slot is found. The coordinator then uses the information of all these nodes and makes a new node list to start a new cycle.

Drawbacks: The packet drop ratio can be higher in dense traffic scenarios because there are high chances of collision in $p-m$ slots. Also, there are high chances that non-interfering sources have to retransmit many times to find a suitable slot. 
11) TAD MAC [46]: TAD MAC works on adaptive algorithm and allows nodes to adapt their wakeup and sleep patterns depending on traffic behavior. It consists of two phases. In the first phase, all transmitting nodes wait for a beacon from the coordinator containing ID and transmission schedule. After this stage, the steady phase commences where the coordinator adopts its wakeup interval in such a way that idle listening is minimized. To estimate this traffic, a traffic status register (TSR) is introduced which is responsible for keeping track of each node. When a node receives data it fills its value by ' 1 ' and with ' 0 ' in the case of no data. Each node maintains a TSR bank to keep track of its neighbors. The wakeup interval is calculated using TSR that is divided into two halves and the preference is given to first half (most recent traffic) as compared to the old traffic. Finally adaptive algorithm is applied to calculate wakeup interval depending on TSR value. An influential parameter in the proposed algorithm is consecutive zeros and ones. In case of consecutive zeros, the next wakeup interval should be increased and vice versa.

Drawbacks: TAD MAC converges to steady state using TSR. It requires an exhaustive search to compute the wakeup intervals for the convergence. The presence of symmetrical traffic helps in converging fast to the steady state. However, there can be a significant degradation in energy consumption and latency in the presence of variable traffic traffic coming from the sensors. Also there is no provision for ET.

12) HACMAC [47]: The basic idea behind the HACMAC protocol is to improve the reliability of communication when different human activities disturb Radio Frequency (RF) spectrum without compromising energy efficiency. The nodes are classified into priority and non-priority nodes. The superframe is divided into three parts, EAP, RAP and MAP. In both EAP and RAP, the nodes send ET on the basis of contention. In a MAP, the coordinator decides to use either CSMA/CA, slotted ALOHA or TDMA for nodes to transmit medical data. A beacon is transmitted at the start of each transmission to facilitate the management. HAC-MAC uses Received Signal Strength Information (RSSI) and Packet Delivery Ratio (PDR) to predict the dynamicity of human activities to improve reliability and energy efficiency. It uses three main schemes; qualitative time-slot allocation, $m$-period interleaving and adaptive relay establishment.

Drawbacks: HACMAC generally targets the high PDR and relaibility in communication using a relay. However, additional energy is consumed by using a relay that effects the lifetime of the sensors. Also, there is an absence of any security mechanism.

13) Shakir MAC [48]: A hybrid node prioritization scheme based on IEEE 802.15.6 CSMA/CA to enhance network lifetime by reducing energy consumption. Nodes are prioritized in this scheme at the MAC and physical layers, depending on the UP and transmit power, respectively. At MAC layer, nodes associated with different UPs are prioritized by assigning them different $\mathrm{CW}$ sizes. Furthermore, nodes associated with the same UP are further prioritized based on transmit power. At the start, the path loss is calculated using RSSI through beacon transmission at the physical layer. Node decides whether to take part in contention access depending on predefined threshold values using path loss. The packets with high transmit power participate in contention access while packets with power lower than threshold values are held back. Hence, it reduces the number of participants thus resulting in a lower number of collisions. Channel access priorities are assigned using $\mathrm{CW}$ sizes at MAC layer. Furthermore, this scheme reduces the back-off time in case of an odd number of retransmission failures. This is in contrast to the IEEE 802.15.6 standard where the back-off counter is doubled.

Drawbacks: This scheme requires advance knowledge of node transmission powers on each UP group. Advance knowledge of nodes is a challenging task in the presence of high density and dynamic nodes.

Section II discussed general design challenges of 802.15.6 MAC, however, all of these challenges are not applicable to hybrid MAC protocols. Table II provides a detailed comparison of the aforementioned hybrid MAC protocols in terms of different attributes such as implant type, cooperation enabled, support for body postures, throughput, lifetime etc. It can be seen from the table that the majority of the protocols have employed a combination of CSMA/CA and TDMA for their hybrid MAC design. There are different priorities assigned in these protocols to distinguish ET from normal traffic. The TDMA mode in these protocols is mainly used to segregate and facilitate ET so that collision and access delay will be minimum. The main objectives common to all protocols are to increase throughput and reduce energy consumption (reducing idle listening), hence improving the lifetime of sensors. Almost all the protocols consider a mix of implant and wearable devices along with respective channel models.

\section{A. Open Research Issues}

1) Energy Harvesting: Sensors in WBAN mostly report on a fixed schedule. However, in case of emergency, they are required to report more frequently, thus requiring more energy. From the analysis, it has been observed that low duty cycle sleeping mode is mostly used to extend the life of the sensors. This helps in preserving their battery as these sensors cannot be recharged easily. The provision of EH in WBAN sensor nodes is an alternate way to increase their lifetime and reduce their dependency on a standard battery [49-51]. There are multiple ambient energy sources available such as solar, vibration, sound, RF, thermoelectric, etc [52], [53]. EH enabled sensors require a suitable energy harvester unit; devising such a unit is itself a complex task and is constrained by requirements at MAC layer such as traffic frequency, node priority and protocols [54], [55]. Therefore, development of an efficient energy harvester is one of the potential challenges and its realization can do wonders for future WBAN technology. In addition, RF energy harvesting based energy cooperation can also be availed [56]. 
TABLE II

COMPARISON OF HYBRID MAC PROTOCOLS.

\begin{tabular}{|c|c|c|c|c|c|c|c|c|c|c|c|c|c|}
\hline Name & Year & $\begin{array}{l}\text { Hybrid } \\
\text { Type }\end{array}$ & $\begin{array}{l}\text { Body } \\
\text { Posture }\end{array}$ & Implant & Relay & $\begin{array}{l}\text { Channel } \\
\text { Model } \\
\text { (CM) }\end{array}$ & $\begin{array}{l}\text { Energy } \\
\text { Harvesting }\end{array}$ & Throughput & $\begin{array}{l}\text { Interference- } \\
\text { Results }\end{array}$ & Latency & Security & LifeTime & $\begin{array}{l}\text { Simulator } \\
\text { Type }\end{array}$ \\
\hline MEB-MAC [35] & 2012 & $\begin{array}{l}\text { CSMA/CA } \\
+ \text { TDMA }\end{array}$ & Yes & $\begin{array}{l}\text { In-body, } \\
\text { On-body }\end{array}$ & No & $\begin{array}{l}\text { CM1, } \\
\text { CM2 }\end{array}$ & No & High (ET) & $\begin{array}{l}\text { Yes - Reduced } \\
\text { Interference in } \\
\text { ET }\end{array}$ & $\begin{array}{l}\text { Improved } \\
\text { (ET) }\end{array}$ & No & No & MATLAB \\
\hline P-MAC [36] & 2013 & $\begin{array}{l}\text { CSMA/CA } \\
+ \text { TDMA }\end{array}$ & No & Not Described & No & $\begin{array}{l}\text { Not De- } \\
\text { scirbed }\end{array}$ & No & High (ET) & No & $\begin{array}{l}\text { Improved } \\
\text { (ET) }\end{array}$ & No & Increased & $\begin{array}{l}\text { Not De- } \\
\text { scirbed }\end{array}$ \\
\hline HEH-BMAC [37] & 2013 & $\begin{array}{l}\text { CSMA/CA } \\
+ \text { Polling }\end{array}$ & No & $\begin{array}{l}\text { In-body, } \\
\text { On-body }\end{array}$ & No & $\begin{array}{l}\text { CM1, } \\
\text { CM2 }\end{array}$ & Yes & Average & $\begin{array}{l}\text { Yes - reduced In- } \\
\text { terference in ET }\end{array}$ & $\begin{array}{l}\text { Not } \\
\text { Improved }\end{array}$ & No & Increased & MATLAB \\
\hline MFS-MAC [39] & 2014 & $\begin{array}{l}\text { CSMA/CA } \\
+ \text { TDMA }\end{array}$ & No & On-body & No & CM4 & No & Average & No & $\begin{array}{l}\text { Not } \\
\text { Improved }\end{array}$ & No & Increased & $\begin{array}{l}\text { Not De- } \\
\text { scribed }\end{array}$ \\
\hline PMAC [40] & 2014 & $\begin{array}{l}\text { CSMA/CA } \\
+ \text { TDMA } \\
+ \text { Slotted } \\
\text { ALOHA }\end{array}$ & No & On-body & No & $\begin{array}{l}\text { Not De- } \\
\text { scirbed }\end{array}$ & No & $\begin{array}{l}\text { High (Prior- } \\
\text { ity wise) }\end{array}$ & $\begin{array}{l}\text { Yes- Interference } \\
\text { reduced } \\
\text { corresponding to } \\
\text { priority level }\end{array}$ & $\begin{array}{l}\text { Improved } \\
\text { (Priority } \\
\text { wise) }\end{array}$ & Yes & Increased & $\mathrm{C}++$ \\
\hline AD-MAC [41] & 2015 & $\begin{array}{l}\text { CSMA/CA } \\
+ \text { TDMA }\end{array}$ & No & On-body & No & $\begin{array}{l}\text { CM3, } \\
\text { CM4 }\end{array}$ & No & Average & $\begin{array}{l}\text { Yes- Overall } \\
\text { PDR Increased }\end{array}$ & Improved & No & Increased & OMNET++ \\
\hline A-CSMA-CA [42] & 2015 & $\begin{array}{l}\text { Polling }+ \\
\text { CSMA/CA }\end{array}$ & No & On-body & No & $\begin{array}{l}\text { CM3, } \\
\text { CM4 }\end{array}$ & No & High & $\begin{array}{l}\text { Yes- Interference } \\
\text { reduced in con- } \\
\text { trolled packets }\end{array}$ & $\begin{array}{l}\text { Not } \\
\text { Improved }\end{array}$ & No & Increased & MATLAB \\
\hline Jacob MAC [43] & 2015 & $\begin{array}{l}\text { Polling+ } \\
\text { CSMA/CA }\end{array}$ & No & $\begin{array}{l}\text { In-body, } \\
\text { On-body }\end{array}$ & No & $\begin{array}{l}\text { CM1, } \\
\text { CM2 }\end{array}$ & No & $\begin{array}{l}\text { Tradeoff } \\
\text { (Energy vs } \\
\text { Throughput } \\
\text { vs access } \\
\text { delay) }\end{array}$ & No & $\begin{array}{l}\text { Tradeoff } \\
\text { (Energy vs } \\
\text { Throughput } \\
\text { vs Access } \\
\text { delay) }\end{array}$ & No & $\begin{array}{l}\text { Tradeoff } \\
\text { (Energy } \\
\text { vc } \\
\text { Through- } \\
\text { put vs } \\
\text { Access } \\
\text { delay) }\end{array}$ & $\begin{array}{l}\text { Not De- } \\
\text { scirbed }\end{array}$ \\
\hline LEDA [44] & 2015 & $\begin{array}{l}\text { CSMA/CA } \\
+ \text { TDMA } \\
+ \text { polling }\end{array}$ & No & On-body & No & $\begin{array}{l}\text { CM1, } \\
\text { CM2 }\end{array}$ & No & $\begin{array}{l}\text { High (Dense } \\
\text { Scenarios) }\end{array}$ & $\begin{array}{l}\text { Yes- Interference } \\
\text { reduced }\end{array}$ & Improved & No & Increased & $\begin{array}{l}\text { MIRAI } \\
\text { Simu- } \\
\text { lation } \\
\text { Frame- } \\
\text { work }\end{array}$ \\
\hline CFTIM [45] & 2016 & $\begin{array}{l}\text { CSMA/CA } \\
+ \\
\text { FTDMA }\end{array}$ & Yes & $\begin{array}{l}\text { In-body, } \\
\text { On-body }\end{array}$ & Yes & $\begin{array}{l}\text { CM1, } \\
\text { CM2 }\end{array}$ & No & High & $\begin{array}{l}\text { Yes- Interference } \\
\text { reduced with in- } \\
\text { crease in PDR }\end{array}$ & $\begin{array}{l}\text { Not } \\
\text { Improved }\end{array}$ & No & Increased & $\begin{array}{l}\text { Not De- } \\
\text { scirbed }\end{array}$ \\
\hline TAD-MAC [46] & 2016 & $\begin{array}{l}\text { TDMA }+ \\
\text { CSMA/CA }\end{array}$ & Yes & On-body & No & CM3 & No & Average & $\begin{array}{l}\text { Yes-Interference } \\
\text { reduced with } \\
\text { increase in PDR }\end{array}$ & Improved & No & Increased & WSnet \\
\hline HACMAC [47] & 2016 & $\begin{array}{l}\text { TDMA + } \\
\text { CSMA/CA } \\
+\quad \text { Slotted } \\
\text { ALOHA }\end{array}$ & Yes & $\begin{array}{l}\text { In-body, } \\
\text { On-body }\end{array}$ & Yes & CM2 & No & High & $\begin{array}{l}\text { Yes-Interference } \\
\text { reduced }\end{array}$ & Improved & No & Increased & Castalia \\
\hline Shakir MAC [48] & 2016 & $\begin{array}{l}\text { CSMA/CA } \\
+ \text { Power }\end{array}$ & Yes & On-body & No & $\begin{array}{l}\text { CM1, } \\
\text { CM2 }\end{array}$ & No & High & $\begin{array}{l}\text { Yes-Interference } \\
\text { reduced } \\
\text { by double } \\
\text { prioritization }\end{array}$ & Improved & No & Increased & $\begin{array}{l}\text { OMNET++ } \\
\text { Mixim }\end{array}$ \\
\hline
\end{tabular}


2) Body Posture: Another important consideration for hybrid MAC protocols is the impact of changing body postures [57], [58]. This important consideration that can lead to outages and hence data retransmission [59]. This, in turn, is detrimental to the energy consumption of WBANs. The future growth of WBANs relies on mechanisms that can provide resilience to body postures. One of the possible solutions is to have cooperative communications that can be achieved by relay nodes. A relay can reroute the traffic to less congested paths that result into high PDR and reliability.

3) Cooperative/Opportunistic Communication: From the above analysis, it is derived that very few protocols support cooperative communications. The provision of cooperative communication is mandatory as implants often experience attenuation due to lossy nature of skin, fat, bone mass and tissue layer [60] and wearable devices suffer from low antenna gain [61]. The relay nodes can provide diverse paths to overcome outages and also retransmit on behalf of source nodes to conserve energy [62-64]. Due to energy limitations, the relay node can employ opportunistic behavior to transmit its own data along with the source [65-67]. This behavior can be further exploited by enabling the MAC layer to support data combining techniques such as network coding [68-70], hierarchical modulations and superposition coding [71], [72].

4) Offered Traffic or Traffic Behaviour: This can also improve the overall connectivity and scalability of the network. In general, the handling of ET is important and critical [73], [74]. The $\mathrm{CW}$ ranges are used to distinguish between ET and normal traffic. Some protocols used 802.15.6 defined $\mathrm{CW}$ sizes while some used custom defined window sizes. In future, a CW with optimal ranges can be developed where throughput will be maximum or it can be designed according to application nature. In addition, it is also important to give due weightage and consideration of the sensor priorities defined in the standard as this depicts the volume and nature of the traffic generated by them. Furthermore, the concept of data aggregation [75] should be employed to improve the performance of the system. It includes data coming from different node, elimination of redundancy, minimizing the number of transmissions and energy. It also includes finding the optimal route from multiple sources to a single destination.

5) Intra/Inter WBAN Interference: Most of the protocols studied above try to eliminate intra-WBAN interference in ET only. However, this is not realistic as most of the traffic volume is normal traffic, which can significantly reduce the throughput, and hence overall performance of a WBAN. Further, it is also important to have smooth coexistence mechanisms with neighboring WBANs to avoid inter-WBAN interference employing standard methods in [42], [76].

6) Security: Security is another important concern for WBANs due to huge amount of sensitive and critical data being generated and transmitted by the sensors [22], [23], [77]. The expectation is to ensure confidentiality, integrity, availability and authentication of this sensitive data [78]. Most of the hybrid MAC protocols discussed above neglect security. There is a good scope to incorporate security mechanisms such as encryption (for confidentiality), intrusion detection (for availability) and public key cryptography (for authentication) in existing hybrid MAC protocols [22], [79]. It is also possible to develop improved and energy efficient security mechanisms for future hybrid MAC designs.

7) Error Correction and Retransmission Strategies: Most of the hybrid MAC protocols use CSMA/CA, so they incur collisions, which requires retransmission of the data. Error correction algorithms provide a way to avoid retransmissions, thus resulting in better energy consumption [80], [81]. Another way of approaching this problem is by reducing collisions by changing $\mathrm{CW}$ ranges, applying AIMD and adjusting superframe phases according to the requirements. The standard proposes use of Hybrid Automatic Repeat Request (ARQ) schemes for retransmissions which can be further exploited in the development of energy efficient and cooperative retransmission schemes [82], [83].

8) Compatibility and Communication with Nanodevices: Implanted nanosensors provide cellular level precision in measurement and actuation as compared to traditional sensors. Usage of traditional sensors for invasive applications is a challenging and painful task as it requires penetration and piercing of the human body. Nanodevices can overcome the above challenges as the size of a device ranges from 1-100 nm. Theses nanosensors support three modes of communication; mechanical, electromagnetic and molecular communication. Only molecular communication is feasible for in-body communication among different nanosensors as mechanical and electromagnetic communications have limitations [12] [84]. However, there are some major differences between nanonetworks and traditional WBAN. For example, WBAN uses electromagnetic waves as a communication carrier as compared to molecules used in nanonetworks. A major limitation of molecules is their finite nature (A non renewable resource that does not renew itself at a sufficient rate for sustainable economic extraction in meaningful human time-frames). In addition, WBANs use electromagnetic signals while nanonetworks use chemical signals. The message is transmitted in the form of bits in WBAN while a molecule message is used in nanonetworks. A molecule has three advantages associated with it [85]. First, it has a common predefined structure that causes its easy recognition. Secondly, the molecular message is eliminated at the time of decoding at the receiver side. The third advantage is that it does not react with other molecules in the medium. In addition, transmission speed in WBANs is high (close to the speed of light) as compared to very low molecular transmission speed in nanonetworks. Electromagnetic field and signals can cause noise in WBANs. In contrast, the noise in nanonetworks is due to particles and molecules in the medium [84]. Even though there is a major difference between nano and traditional sensors, nanosensors along with WBAN can provide cell level support. For example, they are capable of responding to the malicious cells that result in the treatment of the disease such as cancer. Use of nanodevices along with WBAN can revolutionize the medical field. However, the problem of molecular transmission is that it does not follow the traditional network layer structure. Therefore, it is unable to support communication between the hub and nanodevices. Hence, the development of a layered architecture that includes routing protocols and medium access protocols is desired to 
facilitate communication between hub and nanodevices.

9) ETSI Smart Body Area Network (smartBAN): ETSI SmartBAN is the latest standard to facilitate medical applications such as health and vital monitoring [86], [87]. The basic aim of the standard is 1) To design an ultra-low power physical layer for on-body communication between hub and sensors, 2) Design low complexity MAC and routing protocols for smartBANs and 3) Enhanced robustness in presence of interference. The main agenda behind the development of this standard is to make it lightweight and less complex. In addition, it overcomes heterogeneity problems with the introduction of common semantic approach. In this approach, an open data model is dedicated to smart-BAN with the capability of conflict resolution and similarity detection [88]. This standard will be wore robust and energy efficient in future. However, this standard is still under development and can be really useful in the future for manufacturing of health related applications.

10) Backoff Alogorithm in IEEE 802.15.6 WBAN: Generally, Binary Exponential Backoff (BEB) algorithm is used in IEEE 802.15.6 WBAN [89]. The major drawback of BEB is overlapping backoff assignment that causes collisions in WBAN. To resolve this problem, BEB exponentially increases the $\mathrm{CW}$ value, however, it introduces the large delays in the transmission. Therefore, an efficient backoff algorithm is needed to resolve these problems [89], [90].

\section{Conclusions}

WBAN is enhancing the development of various medical and non-medical applications. This has lead to new sets of specifications and requirements at the MAC layer and subsequently the development of IEEE 802.15.6 standard in 2012. Along with the other specifications, this standard described basic MAC layer mechanisms to facilitate the development of application aware WBAN MAC protocols. This paper focuses on a class of MAC protocols, hybrid MAC protocol, which combines the feature of basic MAC layer mechanisms. A detailed comparison is carried out to determine the utility of different hybrid MAC protocols in terms of desired network QoS parameters such as throughput, access delay, lifetime, security, interference mitigation and provision of WBAN specific requirements such as body postures, implant type, cooperation, and channel type. Majority of the hybrid MAC protocols in the existing literature focus on network QoS whereas only a very few consider WBAN specific requirements. Generally, all the hybrid MAC protocols are ET centric with little or no attention to normal traffic and security. A flexible application aware hybrid MAC design to adapt to different QoS parameters is neglected in the majority MAC protocols. An effort towards a flexible design is Jacob MAC in which one can select different ratios of RAP and polling to achieve different QoS specifications. Another Cross-layer prospective using physical and MAC layers to improve performance are presented in Shakir MAC.

The provision to cater for WBAN specific requirements such as body postures, implant type, cooperation, and channel type in hybrid MAC protocols is mandatory to meet the functional requirements of WBAN devices that directly effects the network QoS parameters. Efficient methods such as cooperation, interference management and retransmission strategies can be used to provide cover for changes in body postures and the resulting channel conditions. The EH aware hybrid MAC protocols is a way forward to not only meet the network QoS parameters but can also help in compensating the WBAN specific requirements.

\section{ACKNOWLEDGMENTS}

This project has received funding from the European Union's Horizon 2020 research and innovation program under grant agreement No 668995. This material reflects only the authors view and the EC Research Executive Agency is not responsible for any use that may be made of the information it contains. This work has also received funding from TUT baseline project B38.

\section{REFERENCES}

[1] U. N. of Economic and P. D. Social Affairs, "World population ageing 2013; technical report, st/esa/ser.a/348," United Nations Publication: New York, NY, USA, Tech. Rep., 2013.

[2] W. H. Organization, "Global status report on noncommunicable diseases," WHO Press: Geneva, Switzerland, Tech. Rep., 2014.

[3] A. Chatterjee, S. Kubendran, J. King, and R. DeVol, "Chronic disease and wellness in america, measuring the economic burden in a changing nation; technical report," Milken Institute: Santa Monica, CA, USA, Tech. Rep., 2014.

[4] E. Kartsakli, A. S. Lalos, A. Antonopoulos, S. Tennina, M. D. Renzo, L. Alonso, and C. Verikoukis, "A survey on $\mathrm{m} 2 \mathrm{~m}$ systems for mhealth: A wireless communications perspective," Sensors, vol. 14, no. 10, pp. 18 009-18 052, 2014. [Online]. Available: http://www.mdpi.com/1424$8220 / 14 / 10 / 18009$

[5] M. Sudjai, L. Tran, and F. Safaei, "On the energy efficiency of adaptive wban systems for mhealth services," EAI Endorsed Transactions on Pervasive Health and Technology, vol. 17, no. 9, 32017.

[6] M. M. Alam, H. Malik, M. I. Khan, T. Pardy, A. Kuusik, and Y. L. Moullec, "A survey on the roles of communication technologies in iotbased personalized healthcare applications," IEEE Access, vol. 6, pp. 36611-36 631, 2018

[7] G. Fortino, S. Galzarano, R. Gravina, and W. Li, "A framework for collaborative computing and multi-sensor data fusion in body sensor networks," Information Fusion, vol. 22, pp. 50-70, 2015.

[8] G. Fortino, R. Giannantonio, R. Gravina, P. Kuryloski, and R. Jafari, "Enabling effective programming and flexible management of efficient body sensor network applications," IEEE Transactions on HumanMachine Systems, vol. 43, no. 1, pp. 115-133, 2013.

[9] S. Patel, K. Lorincz, R. Hughes, N. Huggins, J. Growdon, D. Standaert, M. Akay, J. Dy, M. Welsh, and P. Bonato, "Monitoring motor fluctuations in patients with parkinson disease using wearable sensors," IEEE Transactions on Information Technology in Biomedicine, vol. 13, no. 6, pp. 864-873, Nov 2009.

[10] C. A. Otto, E. Jovanov, and A. Milenkovic, "A wban-based system for health monitoring at home," in $20063 r d$ IEEE/EMBS International Summer School on Medical Devices and Biosensors, Sept 2006, pp. 20-23.

[11] R. Gravina, P. Alinia, H. Ghasemzadeh, and G. Fortino, "Multi-sensor fusion in body sensor networks: Stateof-the-art and research challenges," Information Fusion, vol. 35, pp. $68-80,2017 . \quad$ [Online]. Available: http://www.sciencedirect.com/science/article/pii/S156625351630077X

[12] S. Sarkar and S. Misra, "From Micro to Nano: The Evolution of Wireless Sensor-Based Health Care," IEEE Pulse, vol. 7, no. 1, pp. 21-25, 2016.

[13] S. Movassaghi, M. Abolhasan, J. Lipman, D. Smith, and A. Jamalipour, "Wireless body area networks: A survey," IEEE Communications Surveys Tutorials, vol. 16, no. 3, pp. 1658-1686, Third 2014.

[14] O. Hamdi, M. A. Chalouf, D. Ouattara, and F. Krief, "ehealth: Survey on research projects, comparative study of telemonitoring architecture and main issues," Journal of Network and Computer Applications, vol. 46, no. Supplement C, pp. 100 - 112, 2014. [Online]. Available: http://www.sciencedirect.com/science/article/pii/S1084804514001672 
[15] A. S. Lalos, A. Antonopoulos, E. Kartsakli, M. D. Renzo, S. Tennina, L. Alonso, and C. Verikoukis, "Rlnc-aided cooperative compressed sensing for energy efficient vital signal telemonitoring," IEEE Transactions on Wireless Communications, vol. 14, no. 7, pp. 3685-3699, July 2015.

[16] Wireless medium access control (MAC) and physical layer (PHY) specifications for low rate wireless personal area networks (WPANs) (amendment of IEEE Std 802.15.4-2003). IEEE standard 802.15.4, 2006.

[17] B. Rose, "Home networks: A standards perspective," Comm. Mag., vol. 39, no. 12, pp. 78-85, Dec. 2001. [Online]. Available: http://dx.doi.org/10.1109/35.968816

[18] S. Nepal, S. Dahal, and S. Shin, "Does the ieee 802.15.4 mac protocol work well in wireless body area networks?" Journal of Advances in Computer Networks, vol. 4, no. 1, pp. 52-58, 2016.

[19] IEEE Standard for Local and Metropolitan Area Networks-Part 15.6: Wireless Body Area Networks. IEEE Std 802.15.6, 2012.

[20] M. Alam, O. Berder, D. Menard, T. Anger, and O. Sentieys, "A hybrid model for accurate energy analysis of wsn nodes," EURASIP Journal on Embedded Systems, vol. 2011, no. 1, p. 307079, 2011.

[21] S. Ullah, M. Mohaisen, and M. A. Alnuem, "A review of ieee 802.15.6 mac, phy, and security specifications," International Journal of Distributed Sensor Networks, vol. 9, no. 4, p. 950704, 2013. [Online]. Available: http://dx.doi.org/10.1155/2013/950704

[22] S. Al-Janabi, I. Al-Shourbaji, M. Shojafar, and S. Shamshirband, "Survey of main challenges (security and privacy) in wireless body area networks for healthcare applications," Egyptian Informatics Journal, pp. -, 2016. [Online]. Available: http://www.sciencedirect.com/science/article/pii/S1110866516300482

[23] M. Rahman and S. Sampalli, "A hybrid key management protocol for wireless sensor networks," pp. 769-776, 2012.

[24] A. Rahim, N. Javaid, M. Aslam, Z. Rahman, U. Qasim, and Z. A. Khan, "A comprehensive survey of mac protocols for wireless body area networks," in 2012 Seventh International Conference on Broadband, Wireless Computing, Communication and Applications, Nov 2012, pp. 434-439.

[25] V. R. Karuppiah Ramachandran, E. D. Ayele, N. Meratnia, and P. J. Havinga, "Potential of wake-up radio-based mac protocols for implantable body sensor networks (ibsn)-a survey," Sensors (Switserland), vol. 16, no. 12, p. 2012, November 2016. [Online]. Available: http://doc.utwente.n1/102922/

[26] A. Boulis, D. Smith, D. Miniutti, L. Libman, and Y. Tselishchev, "Challenges in body area networks for healthcare: the mac," IEEE Communications Magazine, vol. 50, no. 5, pp. 100-106, May 2012.

[27] J. Y. Khan and M. R. Yuce, "Wireless body area network (wban) for medical applications," in New Developments in Biomedical Engineering, Nov 2010, pp. 434-439.

[28] S. Galzarano, G. Fortino, and A. Liotta, "A learning-based mac for energy efficient wireless sensor networks," International Conference on Internet and Distributed Computing Systems. [Online]. Available: http://hdl.handle.net/10545/622619

[29] N. Bradai, L. C. Fourati, and L. Kamoun, "Investigation and performance analysis of $\{\mathrm{MAC}\}$ protocols for $\{$ WBAN $\}$ networks," Journal of Network and Computer Applications, vol. 46, pp. $362-373,2014$. [Online]. Available: http://www.sciencedirect.com/science/article/pii/S1084804514002197

[30] U. K. Singh, K. C. Phuleriya, and L. Laddhani, "Study and analysis of mac protocols design approach for wireless sensor networks," 2012.

[31] S. K. Upadhayay and M. Gupta, "Mac (medium access control) protocols for wireless body area networks: A survey," Journal of Emerging Technologies and Innovative Research (JETIR), vol. 2, no. 6, 2015.

[32] M. azhari, A. Toumanari, and R. Latif, "Study of mac protocols for mobile wireless body sensor networks," Network and Complex Systems, vol. 4, no. 4, 2014.

[33] M. M. Alam and E. B. Hamida, "Surveying wearable human assistive technology for life and safety critical applications: Standards, challenges and opportunities," Sensors, vol. 14, no. 5, pp. 9153-9209, 2014. [Online]. Available: http://www.mdpi.com/1424-8220/14/5/9153

[34] S. A. Gopalan and J.-T. Park, "Energy-efficient mac protocols for wireless body area networks: Survey," in International Congress on Ultra Modern Telecommunications and Control Systems, Oct 2010, pp. 739-744.

[35] M. A. Huq, E. Dutkiewicz, G. Fang, R. P. Liu, and R. Vesilo, "Meb mac: Improved channel access scheme for medical emergency traffic in wban," in 2012 International Symposium on Communications and Information Technologies (ISCIT), Oct 2012, pp. 371-376.

[36] N. Bradai, L. C. Fourati, S. Boudjit, and L. Kamoun, "New priority mac protocol for wireless body area networks," in Proceedings of the 3rd ACM MobiHoc Workshop on Pervasive Wireless Healthcare, ser. MobileHealth '13. New York, NY, USA: ACM, 2013, pp. 1-6. [Online]. Available: http://doi.acm.org/10.1145/2491148.2491149

[37] E. Ibarra, A. Antonopoulos, E. Kartsakli, and C. Verikoukis, "Energy harvesting aware hybrid mac protocol for wbans," in 2013 IEEE 15th International Conference on e-Health Networking, Applications and Services (Healthcom 2013), Oct 2013, pp. 120-124.

[38] D.-M. Chiu and R. Jain, "Analysis of the increase and decrease algorithms for congestion avoidance in computer networks," Computer Networks and ISDN Systems, vol. 17, no. 1, pp. $1-14,1989$. [Online]. Available: http://www.sciencedirect.com/science/article/pii/0169755289900196

[39] J. S. Choi and J. G. Kim, "An improved mac protocol for wban through modified frame structure," International Journal of Smart Home, vol. 8 , no. 2, 2014.

[40] S. Ullah, M. Imran, and M. Alnuem, "A hybrid and secure priorityguaranteed mac protocol for wireless body area network," International Journal of Distributed Sensor Networks, vol. 10, no. 2, p. 481761, 2014. [Online]. Available: http://dx.doi.org/10.1155/2014/481761

[41] J. Wang, Y. Xie, and Q. Yi, "An all dynamic mac protocol for wireless body area network," in 11th International Conference on Wireless Communications, Networking and Mobile Computing (WiCOM 2015), Sept 2015, pp. 1-6.

[42] W. Huang and T. Q. S. Quek, "Adaptive csma/ca mac protocol to reduce inter-wban interference for wireless body area networks," in 2015 IEEE 12th International Conference on Wearable and Implantable Body Sensor Networks (BSN), June 2015, pp. 1-6.

[43] A. K. Jacob and L. Jacob, "An investigation into the effectiveness of ieee 802.15.6 mac access methods," in 2015 IEEE International Conference on Signal Processing, Informatics, Communication and Energy Systems (SPICES), Feb 2015, pp. 1-5.

[44] C. Li, X. Yuan, L. Yang, and Y. Song, "A hybrid lifetime extended directional approach for wbans," Sensors, vol. 15, no. 11, pp. 28005 28030,2015

[45] M. J. Ali, H. Moungla, and A. Mehaoua, "Dynamic channel access scheme for interference mitigation in relay-assisted intra-wbans," in 2015 International Conference on Protocol Engineering (ICPE) and International Conference on New Technologies of Distributed Systems (NTDS), July 2015, pp. 1-6.

[46] M. M. Alam, E. B. Hamida, O. Berder, D. Menard, and O. Sentieys, "A heuristic self-adaptive medium access control for resource-constrained wban systems," IEEE Access, vol. 4, pp. 1287-1300, 2016.

[47] V. R. K. Ramachandran, P. J. M. Havinga, and N. Meratnia, "Hacmac: A reliable human activity-based medium access control for implantable body sensor networks," in 2016 IEEE 13th International Conference on Wearable and Implantable Body Sensor Networks (BSN), June 2016, pp. 383-389.

[48] M. Shakir, O. ur Rehman, M. Rahim, N. A. Alrajeh, Z. A. Khan, M. A. Khan, I. A. Niaz, and N. Javaid, "Performance optimization of priority assisted CSMA/CA mechanism of 802.15.6 under saturation regime," Sensors, vol. 16, no. 9, p. 1421, 2016. [Online]. Available: https://doi.org/10.3390/s16091421

[49] P. D. Mitcheson, E. M. Yeatman, G. K. Rao, A. S. Holmes, and T. C. Green, "Energy harvesting from human and machine motion for wireless electronic devices," Proceedings of the IEEE, vol. 96, no. 9, pp. 14571486, Sept 2008.

[50] D. C. Hoang, Y. K. Tan, H. B. Chng, and S. K. Panda, "Thermal energy harvesting from human warmth for wireless body area network in medical healthcare system," in 2009 International Conference on Power Electronics and Drive Systems (PEDS), Nov 2009, pp. 1277-1282.

[51] E. Ibarra, A. Antonopoulos, E. Kartsakli, and C. Verikoukis, "Hehbmac: Hybrid polling mac protocol for wbans operated by human energy harvesting," Telecommun. Syst., vol. 58, no. 2, pp. 111-124, Feb. 2015.

[52] X. Xu, L. Shu, M. Guizani, M. Liu, and J. Lu, "A survey on energy harvesting and integrated data sharing in wireless body area networks," International Journal of Distributed Sensor Networks, vol. 11, no. 10, p. 438695, 2015. [Online]. Available: http://dx.doi.org/10.1155/2015/438695

[53] T. D. Nguyen, J. Y. Khan, and D. T. Ngo, "Energy harvested ieee 802.15.4 wireless body area network," in Proceedings of the 10th EAI International Conference on Body Area Networks, ser. BodyNets '15. ICST, Brussels, Belgium, Belgium: ICST (Institute for Computer Sciences, Social-Informatics and Telecommunications Engineering), 2015, pp. 247-253. [Online]. Available: https://doi.org/10.4108/eai.289-2015.2261429

[54] E. Ibarra, A. Antonopoulos, E. Kartsakli, J. J. P. C. Rodrigues, and C. Verikoukis, "Qos-aware energy management in body sensor nodes 
powered by human energy harvesting," IEEE Sensors Journal, vol. 16, no. 2, pp. 542-549, Jan 2016.

[55] V. Esteves, A. Antonopoulos, E. Kartsakli, M. Puig-Vidal, P. MiribelCatal, and C. Verikoukis, "Cooperative energy harvesting-adaptive mac protocol for wbans," Sensors, vol. 15, no. 6, pp. 12 635-12 650, 2015.

[56] V. Liu, A. Parks, V. Talla, S. Gollakota, D. Wetherall, and J. Smith, Ambient backscatter: Wireless communication out of thin air, 4th ed., 2013, vol. 43, pp. 39-50.

[57] Q. H. Abbasi, A. Alomainy, and Y. Hao, "Effect of human body movements on performance of multiband ofdm based ultra wideband wireless communication system," in 2010 Loughborough Antennas Propagation Conference, Nov 2010, pp. 145-148.

[58] A. Talpur, N. Baloch, N. Bohra, F. K. Shaikh, and E. Felemban, "Analyzing the impact of body postures and power on communication in wban," Procedia Computer Science, vol. 32, pp. 894 - 899, 2014. [Online]. Available: http://www.sciencedirect.com/science/article/pii/S187705091400708X

[59] M. Quwaider, J. Rao, and S. Biswas, "Body-posture-based dynamic link power control in wearable sensor networks," IEEE Communications Magazine, vol. 48, no. 7, pp. 134-142, July 2010.

[60] K. Y. Yazdandoost and K. Sayrafian-Pour, "Channel model for body area network (ban)," 2007.

[61] B. Aslam, U. H. Khan, M. A. Azam, Y. Amin, J. Loo, and H. Tenhunen, "Miniaturized decoupled slotted patch rfid tag antennas for wearable health care," International Journal of RF and Microwave ComputerAided Engineering, September 2016.

[62] A. Manirabona, L. C. Fourati, and S. Boudjit, "Decode and merge cooperative mac protocol for intra wban communication," in 2014 IEEE 16th International Conference on e-Health Networking, Applications and Services (Healthcom), Oct 2014, pp. 146-151.

[63] S. Yousaf, N. Javaid, Z. A. Khan, U. Qasim, M. Imran, and M. Iftikhar, "Incremental relay based cooperative communication in wireless body area networks," Procedia Computer Science, vol. 52, pp. 552 - 559, 2015. [Online]. Available: http://www.sciencedirect.com/science/article/pii/S1877050915008352

[64] E. Kartsakli, A. Antonopoulos, L. Alonso, and C. Verikoukis, "A cloudassisted random linear network coding medium access control protocol for healthcare applications," Sensors, vol. 14, no. 3, pp. 4806-4830, 2014.

[65] U. F. Abbasi, A. Awang, and N. H. Hamid, "A cross-layer opportunistic mac/routing protocol to improve reliability in wban," in The 20th AsiaPacific Conference on Communication (APCC2014), Oct 2014, pp. 3641

[66] Y. Zhou, Z. Sheng, V. C. M. Leung, and P. Servati, "Beacon-based opportunistic scheduling in wireless body area network," in 2016 38th Annual International Conference of the IEEE Engineering in Medicine and Biology Society (EMBC), Aug 2016, pp. 4995-4998.

[67] M. Waheed, R. Ahmad, W. Ahmed, M. Drieberg, and M. Alam, "Towards efficient wireless body area network using two-way relay cooperation," Sensors, vol. 18, no. 2, p. 565, 2018.

[68] X. Wang, J. Li, and M. Guizani, "Ncac-mac: Network coding aware cooperative medium access control for wireless networks," in 2012 IEEE Wireless Communications and Networking Conference (WCNC), April 2012, pp. 1636-1641.

[69] E. G. Datsika, A. Antonopoulos, N. Zorba, and C. V. Verikoukis, "Adaptive cooperative network coding based mac protocol for deviceto-device communication," in ICC, 2015.

[70] S. Tennina, M. Santos, A. Mesodiakaki, P. V. Mekikis, E. Kartsakli, A. Antonopoulos, M. D. Renzo, A. Stavridis, F. Graziosi, L. Alonso, and C. Verikoukis, "Wsn4qol: Wsns for remote patient monitoring in e-health applications," in 2016 IEEE International Conference on Communications (ICC), May 2016, pp. 1-6.

[71] J. H. Wui and D. Kim, "Opportunistic cognitive relaying with network and superposition coding for multiple secondary receivers in primary mac," in 2012 1st IEEE International Conference on Communications in China (ICCC), Aug 2012, pp. 625-629.

[72] J. Feng, R. Zhang, and L. Hanzo, "A spectrum leasing cooperative medium access protocol and its stability analysis," IEEE Transactions on Vehicular Technology, vol. 61, no. 8, pp. 3718-3730, Oct 2012.

[73] F. Masud, A. H. Abdullah, G. Abdul-Salaam, and F. Ullah, "Traffic adaptive mac protocols in wireless body area networks," in Wireless Communications and Mobile Computing.

[74] S. Nepal, A. Pudasani, and S. Shin, "A fast channel assignment scheme for emergency handling in wireless body area networks," Sensors, vol. 17, no. 3, 2017. [Online]. Available: http://www.mdpi.com/1424$8220 / 17 / 3 / 477$
[75] B. Krishnamachari, D. Estrin, and S. B. Wicker, "The impact of data aggregation in wireless sensor networks," in Proceedings of the 22Nd International Conference on Distributed Computing Systems, ser. ICDCSW '02. Washington, DC, USA: IEEE Computer Society, 2002, pp. 575-578. [Online]. Available: http://dl.acm.org/citation.cfm?id=646854.708078

[76] M. Ali, H. Moungla, M. Younis, and A. Mehaoua, "Inter-wbans interference mitigation using orthogonal walsh hadamard codes," in 2016 IEEE 27th Annual International Symposium on Personal, Indoor, and Mobile Radio Communications (PIMRC), Sept 2016, pp. 1-7.

[77] S. Saleem, S. Ullah, and K. S. Kwak, "Towards security issues and solutions in wireless body area networks," in INC2010: 6th International Conference on Networked Computing, May 2010, pp. 1-4.

[78] V. Mainanwal, M. Gupta, and S. K. Upadhayay, "A survey on wireless body area network: Security technology and its design methodology issue," in 2015 International Conference on Innovations in Information, Embedded and Communication Systems (ICIIECS), March 2015, pp. 15.

[79] M. Masdari, S. Ahmadzadeh, and M. Bidaki, "Key management in wireless body area network: Challenges and issues," Journal of Network and Computer Applications, vol. 91, no. Supplement C, pp. 36 - 51, 2017. [Online]. Available: http://www.sciencedirect.com/science/article/pii/S1084804517301492

[80] D. Gladis and P. Thangavel, "Noise removal using hopfield neural network in message transmission systems," in 2008 Second UKSIM European Symposium on Computer Modeling and Simulation, Sept 2008, pp. 52-57.

[81] D. T. Quan, P. T. Hiep, and R. Kohno, "Performance analysis method for ieee 802.15.6 based wbans with adaptive bch code rates," Wirel. Pers. Commun., vol. 94, no. 3, pp. 605-619, Jun. 2017.

[82] P. Mafole, M. Kissaka, and M. Aritsugi, "Fragment retransmission scheme with enhanced collision avoidance for energy-efficient ieee 802.11 wlans," in 2016 Wireless Days (WD), 2016, pp. 1-4.

[83] X. He and F. Y. Li, "An optimal energy efficient cooperative retransmission mac scheme in wireless networks," in 2011 2nd International Conference on Wireless Communication, Vehicular Technology, Information Theory and Aerospace Electronic Systems Technology (Wireless VITAE), 2011, pp. 1-5.

[84] I. F. Akyildiz, F. Brunetti, and C. Blzquez, "Nanonetworks: A new communication paradigm," Computer Networks, vol. 52, no. $12, \quad$ pp. 2260 - 2279, 2008. [Online]. Available: http://www.sciencedirect.com/science/article/pii/S1389128608001151

[85] A. M. Andrew, "Nanomedicine, volume 1: Basic capabilities, by robert a. freitas jr., landes bioscience, austin, texas, 1999, xxi \&plus; 509 pp., isbn 1-57059-645-x index (hardback, \&dollar;89.000)," Robotica, vol. 18, no. 6, pp. 687-689, Nov. 2000.

[86] Smart Body Area Network (SmartBAN); Low Complexity Medium Access Control (MAC) for SmartBAN. ETSI TS 103325 (V1.1.1) (04-2015).

[87] Smart Body Area Network (SmartBan); Enhanced Ultra-Low Power Physical Layer. ETSI TS 103325 (V1.1.1) (04-2015).

[88] M. Girod-Genet, L. Nachabe Ismail, and B. El Hassan, "ETSI TS 103 378: Smart Body Area Network (SmartBAN) : unified data representation formats, semantic and open data model," Research Report, Dec. 2015.

[89] P. Khan, N. Ullah, F. Ali, S. Ullah, Y.-S. Hong, K.-Y. Lee, and H. Kim, "Performance analysis of different backoff algorithms for wban-based emerging sensor networks," Sensors, vol. 17, no. 3, p. 492, Feb 2017.

[90] A. Saboor, R. Ahmad, W. Ahmed, and M. Alam, "A unique backoff algorithm in ieee 802.15.6 wban," in 2018 IEEE 88th Vehicular Technology Conference (VTC Fall), 2018 